\title{
Cancer Scenario in Kashmir-A Study Conducted in a Tertiary Care Center, Srinagar, Kashmir, India
}

\author{
Dar Abdul Waheed ${ }^{1}$ Saba Sumaira ${ }^{1} \quad$ Lone Mushtaq Ahmad ${ }^{2} \quad$ Qurat Ul Ain ${ }^{3}$ Sanaullah Kuchay ${ }^{1}$ \\ Nazir Ahmad Dar4
}

${ }^{1}$ Department of Radiation Oncology, Government Medical College Srinagar, Jammu and Kashmir, India

2 Department of Medicine, Government Medical College Anantnag,

Address for correspondence Qurat UI Ain, Health Department, Jammu and Kashmir, India (e-mail: wahidwaheeddar@gmail.com).

Jammu and Kashmir, India

3 Health Department, Jammu and Kashmir Health Education, India

${ }^{4}$ Department of Radiation Oncology, Sher E Kashmir Institute of

Medical Sciences Srinagar, Jammu and Kashmir, India

Asian J Oncol 2022;8:61-65.

\begin{abstract}
Background Cancer can have profound social and economic consequences for the people in India, often leading to family impoverishment and societal inequity. Reported age-adjusted incidence rates for cancer are still quite low in the demographically young country. Slightly more than 1 million new cases of cancer are diagnosed every year in a population of 1.2 billion. It accounts for about 23 and $7 \%$ deaths in United States and India, respectively. The world's population is expected to be 7.5 billion by 2020 and approximations predict that about 15.0 million new cancer cases will be diagnosed, with deaths of about 12.0 million cancer patients. Early detection of cancers is a challenging task because clinical symptoms develop slowly.

Objective The aim of the present study was to analyze the cancer scenario in the Kashmir valley.

Materials and Methods This was a retrospective study. So, all patients were included who had histopathologically confirmed neoplasm registered at Regional Cancer Centre of Government Medical College Srinagar, Kashmir between 2015 and 2018. All the patient characteristics including age, sex, and anatomical site of the disease were studied in detail.

Results The number of cancer patients in 2015, 2016, 2017, and 2018 were 230, 239, 391 , and 511, respectively, with a combined total of 1,371. Thus, it is clear from these figures that the number of cancer cases has increased gradually with time. Stomach

Keywords

- cancer

- Kashmir

- cancer scenario cancer is the most common cancer in the Kashmir territory. In males the most common cancer is stomach cancer with $175(12.8 \%)$ reported cases and in females the most common cancer is breast cancer with $151(11 \%)$ reported cases. The male to female ratio was $1.4: 1$
\end{abstract}

DOI https://doi.org/ 10.1055/s-0041-1740107. ISSN 2454-6798. (c) 2021. Spring Hope Cancer Foundation \& Young Oncologist Group of Asia. All rights reserved.

This is an open access article published by Thieme under the terms of the Creative Commons Attribution-NonDerivative-NonCommercial-License, permitting copying and reproduction so long as the original work is given appropriate credit. Contents may not be used for commercial purposes, or adapted, remixed, transformed or built upon. (https://creativecommons.org/ licenses/by-nc-nd/4.0/)

Thieme Medical and Scientific Publishers Pvt. Ltd., A-12, 2nd Floor, Sector 2, Noida-201301 UP, India 
Conclusion A careful reading the reported cancer cases indicates an increased number of cancer patients every year in Indian-occupied Kashmir. Kashmir is a growing state in India playing a crucial role in the development of India and, hence, it needs special attention on this issue. A multidisciplinary approach to cancer treatment is essential and this has to be made available at all regional cancer centers. Cancer control is an area in which we need participation from all sectors of the society.

\section{Introduction}

All across the world, people are facing a wealth of new and challenging environmental problems every day. Pollution of air, water, and soil requires millions of years to recoup. The global burden of cancer continues to increase largely because of the aging and growth of the world's population and an increasing adoption of cancer-causing behaviors, particularly smoking, in economically developing countries. Breast, lung, and colorectal cancers are occurring in high frequencies in many economically developing countries, in addition to the disproportionately high burden of cancers related to infections. ${ }^{1}$ Cancer is a major cause of morbidity and mortality in developing and developed countries alike. ${ }^{2}$ In many low-income and middle-income countries, including India, most of the population do not have access to a well-organized and well-regulated cancer care system. A diagnosis of cancer often leads to catastrophic personal health expenditures. ${ }^{3}$ Population ageing is often assumed to be the main factor driving increases in cancer incidence, death rates, and health care costs. ${ }^{4}$ Cancer is the second most common disease after cardiovascular disorders for maximum deaths in the world. ${ }^{5}$ Cancer accounts for about 23 and 7\% deaths in United States and India, respectively. The world's population is expected to be 7.5 billion by 2020 and approximations predict that about 15.0 million new cancer cases will be diagnosed, with deaths of about 12.0 million cancer patients. ${ }^{6}$ Cancer mortality in India has doubled from 1990 to 2016. India's cancer incidence was estimated at 1.15 million new patients in $2018,{ }^{7}$ and is predicted to be almost double as a result of demographic changes alone by $2040 .{ }^{8}$ Although improvements in living standards and Human Development Index rankings are typically linked to increases in the occurrence of, for example, sex hormone exposure-related cancers, and cancers epidemiologically associated with reduced average family sizes, ${ }^{9}$ the positive gains that economic and social development bring-e.g., improved food quality-normally far outweigh any such costs. The International Agency for Research on Cancer GLOBOCAN project 1 has predicted that India's cancer burden will nearly double in the next 20 years, from slightly over a million new cases in 2012 to more than 1.7 million by 2035 . These projections indicate that the absolute number of cancer deaths will also rise from about $6.80,000$ to 1.2 million in the same period. Here, we review published data on the epidemiology of cancer and the cancer-related burden in Kashmir.

\section{Cancer Incidence and Mortality}

GLOBOCAN estimates that about 14 million new cancer cases were diagnosed worldwide in 2012 and slightly more than 8 million cancer deaths occurred. One million of these new cases and nearly 700,000 of the deaths occurred in India, which is home to about $17 \%$ of the global population . Even in ageadjusted terms, the recorded incidence for India is, at 94 per $1,00,000$ people, only slightly more than half of the world average of 182 per $1,00,000$, and about a third of that recorded in the more developed countries ( 268 per $1,00,000$ ). All cancers in Indian men other than oral, lung, stomach, colorectal, pharyngeal, and esophageal cancers have an incidence of 5 per 1,00,000 men or less. This, according to U.S. and European Union definitions, makes such cancers orphan diseases. Women have an age-adjusted incidence rate of 104.5 per $1,00,000$ women. With the exceptions of breast, cervical, and colorectal cancers, all other cancers in Indian women also have a recorded incidence of less than 5 per 1,00,000 women.

\section{Methods}

This retrospective study was carried out in the Department of Radiation Oncology, Government Medical College Srinagar, Kashmir, India during the period of November 2015 to December 2018. The primary data on cancer incidence were mainly hospital-based and reported from the proportion of cancer patients seen in the department of oncology in the hospital and expressed as percentages. Patients with known case of carcinoma from all ages and both sexes were included in the study. Clinically suspected carcinoma subsequently proved to be nonmalignant lesions after histological examination were excluded from this study.

A retrospective study was conducted to find the information regarding cancer burden in the Kashmir valley.

\section{Statistical Analysis}

Descriptive analysis was used to report the study results. Categorical data were summarized as percentages. We analyzed the cancer characteristics according to age and sex. The aim of the present study was to analyze the cancer burden in the Kashmir valley.

\section{Results}

The data of cancer patients were compiled from 2015 to 2018 in Kashmir and are shown in - Table $\mathbf{1}$ and - Fig 1. The 
Table 1 Year-wise total cancer prevalence in Kashmir valley

\begin{tabular}{|l|l|l|l|l|l|l|}
\hline Year & Number & $\%$ & Male & $\%$ & Female & $\%$ \\
\hline 2015 & 230 & 16.7 & 126 & 54.8 & 104 & 45.2 \\
\hline 2016 & 239 & 17.4 & 106 & 44 & 133 & 56 \\
\hline 2017 & 391 & 28.5 & 209 & 53 & 182 & 47 \\
\hline 2018 & 511 & 37.4 & 359 & 70 & 152 & 30 \\
\hline Total & 1,371 & 100 & 800 & 58 & 571 & 42 \\
\hline
\end{tabular}

Table 2 The different types of cancers observed in the Kashmir valley

\begin{tabular}{|c|c|c|c|c|c|}
\hline Cancer site & Total, $N$ & $\%$ & Site & $N$ & $\%$ \\
\hline Brain & 25 & 2 & Renal & 7 & 0.6 \\
\hline Oral cavity & 40 & 3 & Urinary bladder & 20 & 1.5 \\
\hline Nasopharynx & 36 & 2.6 & Prostrate & 34 & 2.5 \\
\hline Hypopharynx & 38 & 2.7 & Testis & 15 & 1 \\
\hline Larynx & 26 & 2 & Multiple myeloma & 13 & 0.9 \\
\hline Thyroid & 10 & 0.7 & Melanoma & 4 & 0.3 \\
\hline Esophagus & 122 & 9 & Gallbladder & 35 & 2.6 \\
\hline Gastroesophageal junction & 82 & 6 & Ovary & 50 & 3.7 \\
\hline Stomach & 175 & 12.8 & Uterus & 10 & 0.7 \\
\hline Colon & 64 & 4.7 & Cervix & 10 & 0.7 \\
\hline Rectum & 32 & 2.4 & Breast & 151 & 11 \\
\hline Anal canal & 2 & 0.14 & Skin & 15 & 1 \\
\hline Pancreas & 20 & 1.4 & Sarcoma & 6 & 0.4 \\
\hline Urinary bladder & 15 & 1 & Lung & 142 & 10 \\
\hline Hodgkin lymphoma & 110 & 8 & Thymoma & 2 & 0.14 \\
\hline Non-Hodgkin lymphoma & 60 & 4 & Total & 1,371 & $100 \%$ \\
\hline
\end{tabular}

compiled data show that the total number of cancer patients in the period from 2015 to 2018 was 1,371. The number of male and female cancer patients increased continuously up to 2018 , with 800,571 , and 1,371 cases for male, female, and total cancer patients, respectively. Similarly, 230 cancer patients in 2015, 239 cancer patients in 2016, 391 cancer patients in 2017, and 511 cancer patients in 2018 were recorded. Thus, it is clear from these figures that the number of cancer cases has increased gradually with time.

A perusal of these data clearly shows that stomach cancer is the most common cancer in Kashmir territory; however, in males the most common cancer is stomach with 175 (12.8\%) reported cases, followed by lung $142(10 \%)$ and esophagus $122(9 \%)$, and in females the most common cancer is breast with $151(11 \%)$ reported cases, followed by ovary $50(3.7 \%)$,

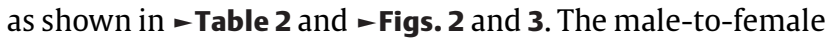
ratio was 1.4:1.

The age group varied from 16 to 80 years with the most common age group being 45 to 64 years, which constitutes 594 (43\%) cases followed by the age group of more than $>64$ years constituting 495 (37\%) cases of both male and female
Table 3 Cancers and their age-standardized incidence rate in 2015 to 2018

\begin{tabular}{|l|l|l|}
\hline Year & Number & Percentage \\
\hline Age $<45$ & 280 & 20 \\
\hline $45-64$ & 594 & 43 \\
\hline$>64$ & 497 & 37 \\
\hline Total & 1,371 & $100 \%$ \\
\hline
\end{tabular}

Note: The most common age group at presentation in our patients was 46-64 years.

populations. However, the age group of $<45$ years constitutes $280(20 \%)$ patients as shown in -Table 3 and -Fig. 4.

\section{Discussion}

In this review, our main finding was that the cancer epidemiological data from Kashmir valley largely were hospital-based, single-center data from tertiary care hospitals. The present 


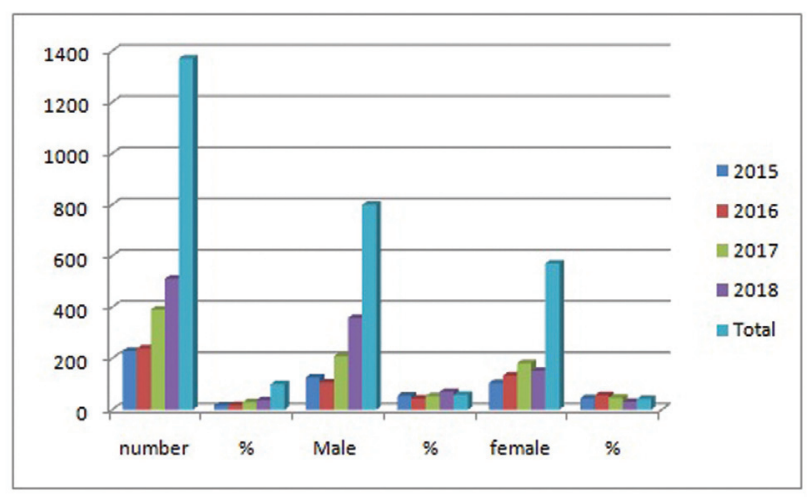

Fig. 1 Total cancer prevalence in Kashmir valley.

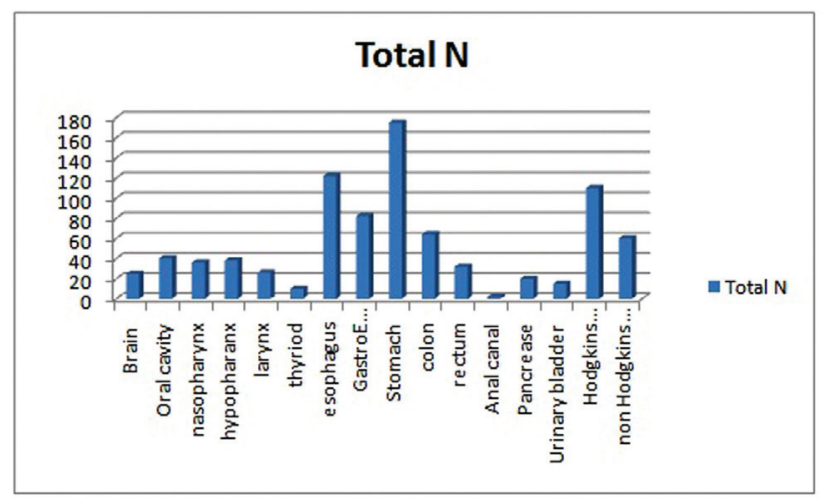

Fig. 2 Different types of cancers observed in the Kashmir valley.

study included 1,371 total number of cancer patients. The mean age of presentation was 69 years in the Western population. The most common age group was 45 to 64 years.

The total number of cancer patients in 2015, 2016, 2017, and 2018 was $230,239,391$, and 511, respectively. The number of male and female cancer patients increased continuously up to 2018 , with 800,571 , and 1,371 cases for male, female, and total cancer patients, respectively.

Besides these, some other types of cancers have been observed in the Kashmir valley. Stomach is one of the most essential organs of the human body, which frequently gets cancer and stands at the fifth position. ${ }^{10}$ The incidence stomach cancer constituted 175 (12.8\%) in Kashmir, which is moderately high, associated with diets and lifestyles. According to data from cancer registries from Kashmir, stomach cancer is the most common cancer among males and the breast cancer is most common cancer among females; however, a study conducted by Gajalakshmi et al showed that esophagus cancer is most common cancer in India and the second most common cause of death in males and fourth most common cause of death in females, and the present study contradicts this study. ${ }^{11}$ Colorectal cancer is a disease that usually affects individuals of age 50 years or more. The likelihood of colorectal cancer diagnosis increases after the age of 40 , increases progressively from age 40 , rising sharply after age $50 ;^{12}$ our study also reveals the same rising trend for colorectal cancer.

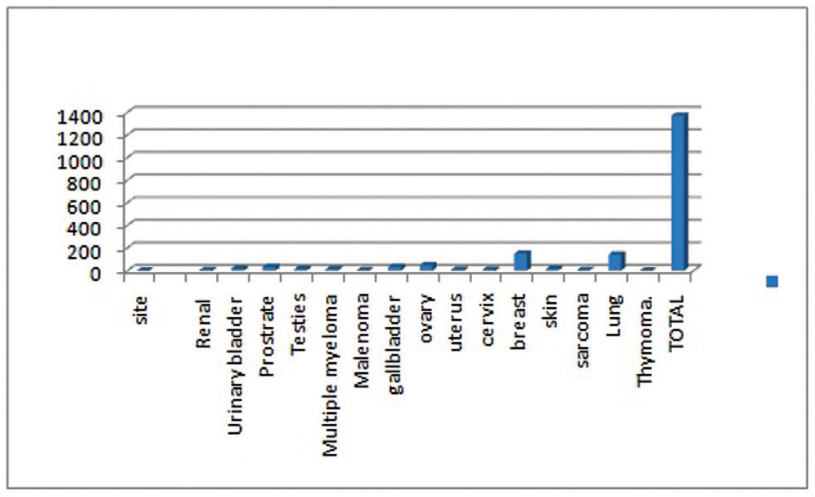

Fig. 3 Different types of cancers observed in the Kashmir valley.

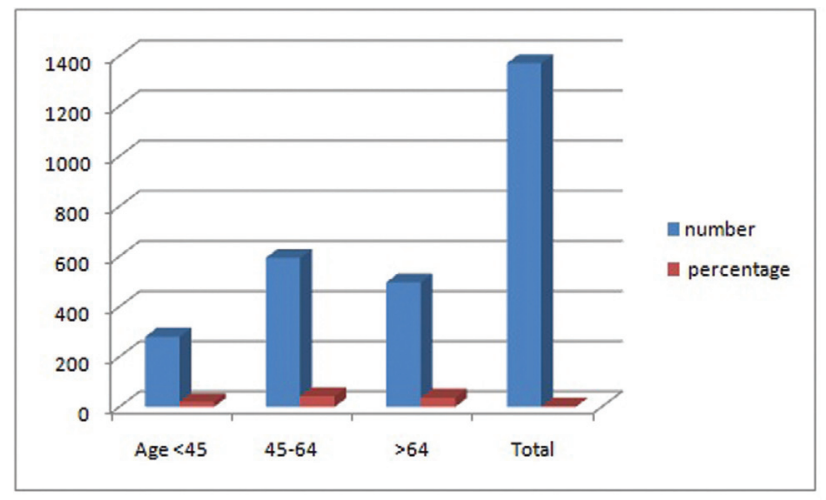

Fig. 4 Cancers and their age-standardized incidence rate from 2015 to 2018 .

Head and neck neoplasms (HNNs) are major forms of cancers in India, which account for nearly 23 and 6\% cancer cases in males and females, respectively. ${ }^{13}$ India is known to have the world's largest reported incidences of HNN in women. ${ }^{14}$ The present study reveals that HNN constitutes $149(11 \%)$ patients; however, it is more prevalent in males than in females.

Breast cancer is the most common malignancy type diagnosed in women in developed countries and the second most common type diagnosed in developing countries. Breast cancer has been described as an alarming health problem in India. ${ }^{15}$ According to reports, breast cancers have badly attacked the women population in India.

In 2012, approximately 145,000 Indian women were diagnosed with breast cancer. Nearly 400,000 of those who had reportedly been diagnosed with breast cancer in the previous 5 years were still alive. In 2009, breast cancer became the most frequently diagnosed form of neoplastic disease in women in India and is now the most common cause of cancer deaths in the country, accounting for more than a fifth of all female cancer mortality. Our study reveals the same results that the most common cancer in females is breast cancer and it is the most common cause of death in females.

However, the actual picture is more complex. In highincome countries, age-standardized cancer mortality is now 
typically decreasing in all age groups, although more than half of all cancer deaths are people older than 70 years. In Kashmir, despite the paucity of data in terms of population coverage, no evidence exists for a decrease in age-standardized cancer mortality rates, and most deaths occur in individuals younger than 70 years.

These differences are only partly due to Kashmir having a relatively younger population compared with high-income states/countries. They are also a product of contrasting causal patterns, with infections and unique local patterns of tobacco use playing a much greater part in causing cancer in Kashmir than in richer states/countries. Poor access to screening and early-stage case-finding services also help to explain the paradox of Kashmir's seemingly low cancer incidence rates but relatively high age-specific death rates. In spite of the great advancements for diagnosis and treatment, cancer is still a big threat to our society.

There was no uniformity in reporting the incidence rates. The hospital-based studies have represented incidence as a percentage of patients treated. The nonuniformity in reporting and predominance of hospital-based registries lead to misrepresentation of the incidence of cancers. Keeping in line with the changing epidemiological picture, the cancer incidence rise was reported in all of our studied manuscripts.

The constraints of our study are more often the patients are referred to outside state, and most of the patients were registered and treated at other cancer center Skims Kashmir valley. Hence, our study group may not exactly reflect the prevalence and incidence of cancer of the whole population in this region. Despite these limitations, our institution being a major oncological center in this region, it may reflect the nature of the disease in this population and emphasizes the significance of early diagnosis by proper and timely evaluation, and management of the disease.

\section{Conclusion}

A careful reading of the above discussion in this article clearly indicates an increased number of cancer patients every year in Indian-occupied Kashmir. Kashmir is a growing state in India playing a crucial role in the development of India and, hence, it needs special attention on this issue. We should create awareness among the public about the cancer havoc and its prevention. Different programs should be started by the government and nongovernmental organizations for creating awareness among public. The diet and lifestyles are important factors to control the spreading of cancers and, hence, Indians should be careful about these facts. Briefly, cancer is disturbing the growing economy of Kashmir, which can be reduced by proper handling of this disease. In view of these facts, it is very important to eradicate this havoc. Let us hope for the best future of Kashmir, which is playing an essential role in the development of India.
Cancer patients are increasing every passing year in Kashmir. Various factors responsible for cancer genesis have been discussed, which need to be controlled for their eradication. India is a growing country playing a crucial role in the development of the whole world, and, hence, it needs to give special attention on this issue. A multidisciplinary approach to cancer treatment is essential and this has to be made available at all regional cancer centers. Cancer control is an area in which we need participation from all sectors of the society.

\section{Conflict of Interest \\ None declared.}

\section{References}

1 Jemal A, Bray F, Center MM, Ferlay J, Ward E, Forman D. Global cancer statistics. CA Cancer J Clin 2011;61(02):69-90

2 Ferlay J, Soerjomataram I, Ervik M, et al. GLOBOCAN 2012 v1.0, Cancer Incidence and Mortality Worldwide: IARC CancerBase No.11. Lyon, France: International Agency for Research on Cancer, 2013. Accessed December 23, 2013 at: http://globocan.iarc.fr

3 Engelgau MM, Karan A, Mahal A. The Economic impact of Noncommunicable Diseases on households in India. Global Health 2012. Doi: $10.1186 / 1744-8603-8-9$

4 Yancik R. Population aging and cancer: a cross-national concern. Cancer J 2005;11(06):437-441

5 Jemal A, Siegel R, Ward E, Murray T, Xu J, Thun MJ. Cancer statistics, 2007. CA Cancer J Clin 2007;57(01):43-66

6 Bray F, Møller B. Predicting the future burden of cancer. Nat Rev Cancer 2006;6(01):63-74

7 India State-Level Disease Burden Initiative Cancer Collaborators. The burden of cancers and their variations across the states of India: the Global Burden of Disease Study 1990-2016. Lancet Oncol 2018;19(10):1289-1306

8 WHO. Global Cancer Observatory, International Agency for Research on Cancer. Available at: https://jco.iarc.fr

9 Bray F, Jemal A, Grey N, Ferlay J, Forman D. Global cancer transitions according to the Human Development Index (20082030): a population-based study. Lancet Oncol 2012;13(08): 790-801

10 Parkin DM, Pisani P, Ferlay J. Global cancer statistics. CA Cancer J Clin 1999;49(01):33-64, 1

11 Gajalakshmi V, Swaminathan R, Shanta V. An independent survey to assess completeness of registration: population based cancer registery, Chennai, India. Asian Pac J Cancer Prev 2001;2(03): 179-183

12 Ries LAG, Melbert D, Krapcho M, et al. SEER Cancer Statistics Review, 1975-2005. National Cancer InstituteBethesda, MD. Available at: https://seer.cancer.gov/csr/1975_2005/

13 Mehrotra R, Singh M, Gupta RK, Singh M, Kapoor AK. Trends of prevalence and pathological spectrum of head and neck cancers in North India. Indian J Cancer 2005;42(02):89-93

14 Sankaranarayanan R, Masuyer E, Swaminathan R, Ferlay J, Whelan S. Head and neck cancer: a global perspective on epidemiology and prognosis. Anticancer Res 1998;18(6B):4779-4786

15 Yeole BB, Kurkure AP. An epidemiological assessment of increasing incidence and trends in breast cancer in Mumbai and other sites in India, during the last two decades. Asian Pac J Cancer Prev 2003;4(01):51-56 